\title{
Antídoto y utopía \\ Una lectura de la dimensión comunitaria en el liberalismo clásico.
}

\author{
Ana Lucía Grondona ${ }^{1}$
}

\begin{abstract}
"Las poblaciones que alguna vez estuvieron bajo el tutelaje del estado social han de ser liberadas para encontrar su propio destino. Sin embargo, al mismo tiempo, han de hacerse responsables por su destino y el de la sociedad como un todo. La política ha de volver a la sociedad misma, pero ya no bajo la forma social: en la forma de individual moral, responsabilidad organizacional y comunidad ética".
\end{abstract}

(Rose 2000: 1400, itálica nuestra)

Resumen

El presente trabajo aborda una lectura en clave comunitarista de dos autores centrales del liberalismo clásico: Alexis de Tocqueville y John Locke. Ello a fin de poner en cuestión el diagnóstico según el cual la articulación entre "comunitarismo" y "liberalismo" corresponde a una singularidad del gobierno neoliberal de las poblaciones.

El artículo está organizado en cuatro secciones, en la primera se introducen los términos generales del problema; en la segunda, se analiza el diagnóstico de Alexis de Tocqueville a porpósito de la "cuestión social", para analizar, en la tercera, los antídotos "comunitarista" propuestos para administrarla. En la cuarta sección, se aborda la dimensión utópica que sostiene este planteo y el de John Locke. Por último, en unas breves reflexiones finales, se retoman las preguntas formuladas al comienzo del recorrido.

\section{Presentación del problema}

En los últimos años las ciencias sociales han anunciado con insistencia el "revival" de la comunidad (de Marinis, 2005). Según Nikolas Rose (1996), éste responde a la mutación de la matriz de gobierno de las poblaciones y a la consolidación de un nuevo esquema en el que prima la responsabilización

\footnotetext{
1 Dra. en Ciencias Sociales de la Universidad de Buenos Aires-Argentina. Instituto de Investigacion. Gino Germani. Universidad de Buenos AiresArgentina. Centro Cultural de la Cooperación Floreal Gorini. Agradezco a Pablo de Marinis y a Victoria Haidar por los comentarios a versiones previas de este trabajo. Este texto se ha alimentado de las reflexiones que desde hace algunos años viene realizando el equipo de "Teorías sociológicas de la comunidad" dirigido por de Marinis en el IIGG.
} 
GRONDONA, Ana Lucia. Antídoto y utopía: Una lectura de la dimensión comunitaria en el liberalismo clásico.

individual, por un lado, y el llamado a hacer de las comunidades el espacio de sociabilidad moral, por el otro.

Respecto del uso de este polisémico término, nos ajustamos a la definición que el citado autor recupera de Etzioni, según la cual "la comunidad es definida por dos características: primero, como una red de relaciones afectivas entre grupos de individuos, relaciones que frecuentemente se superpone y refuerzan (...), y segundo, una medida de compromiso a un juego (set) de valores, normas y sentidos compartidos, y una historia e identidades compartidas- en resumen, una cultura" (Etzioni, 1997 p.127, en Rose , 2000 p141). Fundamentalmente, entonces, entendemos que el espacio de "lo comunitario" se contrapone al registro instrumental de "lo social" y se muestra como un lugar de afectos, identificaciones inmediatas, de reconocimiento, como un espacio de sociabilidad "natural".

La asimilación inmediata entre liberalismo ${ }^{2}$ e individualismo ${ }^{3}$ ha sido una operación casi automática para el sentido común. A tal punto que a la hora de analizar las nuevas derechas resulta común que se las describa como resultado de una articulación de dos formaciones discursivas en principio antagónicas: el individualismo liberal, que interpela a los sujetos a asumir el gobierno de sí de modo responsable y autónomo, por un lado, y la convocatoria neoconservadora a "revivir" la comunidad como espacio de inclusión y de gestión del conflicto, del otro (vgr. Bernstein, 1998).

En este trabajo propondremos algunas objeciones a este tipo de análisis. Para ello, comenzaremos por indagar la relación entre libertad individual y comunidad en la teoría política y social de Alexis de Tocqueville. Hemos elegido a este autor atendiendo al modo en que, desde una perspectiva liberal, plantea la cuestión social; pero sobre todo, a las estrategias "comunitaristas"

\footnotetext{
2 Siguiendo a Michel Foucault (2008) entendemos que "es preciso entender esta palabra en un sentido muy amplio:1) Aceptación del principio de que en alguna parte debe haber una limitación del gobierno, y que no sea simplemente un derecho externo.2) El liberalismo es también una práctica: ¿dónde encontrar exactamente el principio delimitación del gobierno y cómo calcular los efectos de esa limitación?3) El liberalismo es, en un sentido más restringido, la solución consistente en limitar al máximo las formas y los ámbitos de acción del gobierno.4) Para terminar, el liberalismo es la organización de los métodos de transacción aptos para definir la limitación de las prácticas de gobierno:- constitución, parlamento;- opinión, prensa;- comisiones, investigaciones (...) Se caracteriza por el hecho de que, en lugar de tropezar con límites formalizados por jurisdicciones, se da a sí misma límites intrínsecos formulados en términos de veridicción" (2008: 39).

3 Hacemos uso este término de un modo genérico, para referirnos a las perspectivas según las cuales "el individuo" constituye el fundamento de toda ley y a las cuales, en virtud de ello mismo, les resulta problemática la relación entre diversos individuos en una comunidad (Ferrater Mora, 1964 p.922)
} 
que propone para enfrentarla, en el contexto de la naciente invención de "lo social" como modo generalizado de administrar esta tensión (Donzelot, 1995).

Ahora bien, además de dar cuenta del tono "comunitarista" de las alternativas propuestas por Tocqueville, también presentaremos la hipótesis de que éstas se sostienen sobre el trasfondo de una "utopía comunitarista", en la que opera la construcción de un pasado comunitario idílico y añorado. A fin de investigar con mayor profundidad esta figura utópico-comunitaria, continuaremos indagando la relación entre libertad individual y comunidad en el pensamiento de John Locke. Con ello pretendemos mostrar que este horizonte no resulta una singularidad presente en Tocqueville, sino una dimensión cuya relevancia en la formación discursiva liberal debiera ser analizada más extensivamente.

Este trabajo no pretende una exégesis exhaustiva de los textos ni de los autores seleccionados, sino dejar planteada la pregunta acerca de si "lo comunitario" más que un "(re)descubrimiento" post-social del neoliberalismo, no es un viejo antídoto liberal contra los riesgos del gobierno de tipo "social".

Con gobierno de tipo social nos referimos al modo singular de diagnóstico e intervención sobre las poblaciones que se consolidaba entre fines del siglo XIX y comienzos del XX. En efecto, la práctica efectiva del gobierno liberal de las poblaciones que había nacido en el siglo XVIII implicó, en su despliegue y como contracara, la proliferación progresiva de mecanismos que Foucault denominó "liberógenos" (2008: 91). Nos referimos aquí a los dispositivos desarrollados a partir de las crisis económicas de fines del XIX, basados en la "invención de la solidaridad" (Donzelot, 2007). Estas intervenciones buscaban dar respuesta a los "dislocamientos" generados a partir del despliegue del mercado, que ponía en riesgo la cohesión social y, con ello, también su propio funcionamiento (Polanyi, 1989).

Ahora bien si por un lado estos mecanismos "compensatorios" parecían extender la libertad a nuevos ámbitos (libertad de trabajo, libertad de consumo), también la "amenazaban" desde el interior, pues consolidaban ámbitos sustraídos al mercado y regidos por el orden burocrático de un Estado crecientemente centralizado.

Como veremos a continuación, Tocqueville se mostraría singularmente preocupado por dos amenazas que ya avizoraba desde su tiempo: la de la 
GRONDONA, Ana Lucia. Antídoto y utopía: Una lectura de la dimensión comunitaria en el liberalismo clásico.

revuelta de los pobres y la de la centralización de un Estado cada vez más autoritario. Frente a ello, la re-creación de ámbitos comunitarios albergaba la promesa de resolver en un mismo movimiento las amenazas a la libertad y a la cohesión social.

\section{Alexis de Tocqueville: las amenazas a la libertad y sus remedios}

Alexis de Tocqueville es uno de los primeros promotores de las "organizaciones secundarias" como condición misma de la libertad individual en los tiempos modernos. En este sentido, los ámbitos comunitarios debían cumplir un papel en el nuevo ordenamiento social, amenazado por una cuestión cabal:

Cuando la mayor parte de los ciudadanos logran una condición poco más o menos semejante; y la igualdad es un hecho antiguo y admitido, la opinión común (...) señala de un modo general al valor de cada hombre ciertos límites, fuera de los cuales es difícil que permanezca mucho tiempo. En vano, la pobreza y la riqueza, el mando y la obediencia separan accidentalmente a estos dos hombres a gran distancia, pues es la opinión pública, que se funda en el orden común de las cosas, los acerca al mismo nivel y, a pesar de la desigualdad real de sus condiciones crea una especie de igualdad imaginaria (Tocqueville, 1957 p.533, itálica nuestra)

Justamente en la brecha entre la desigualdad real y la igualdad imaginaria que se configuró la "cuestión social" como tensión política permanente. Tocqueville también advierte el principal riesgo vinculado a ella: la imprevisibilidad de los proletarios, de "aquellos que no tienen bajo el sol otra propiedad que aquella de sus brazos" (Tocqueville, 2006b p.5, itálica nuestra). En efecto, el hiato entre la desigualdad material y la igualdad imaginaria ponía en riesgo la estabilidad del orden.

Nuestro autor no sólo describió estos males, sino que se preguntó también por sus causas, señalando como la principal entre ellas al proceso de democratización social creciente ${ }^{4}$. En efecto, desde la perspectiva de

\footnotetext{
4 "El desarrollo gradual de la igualdad de condiciones es, pues, un hecho providencial, y tiene las siguientes características: es universal, durable, escapa a la potestad humana y todos los acontecimientos, como todos los hombres, sirven para su desarrollo ¿Es sensato creer que un movimiento social que viene de tan lejos, puede ser detenido por los esfuerzos de una generación? ¿Puede pensarse que después de haber destruido el feudalismo y vencido a los reyes, la democracia retrocederá ante los burgueses y los ricos? ¿Se detendrá ahora que se ha vuelto tan fuerte y sus adversarios tan débiles?" (Tocqueville, 1985 p.11)
} 
Tocqueville, el decurso de la historia estaba signado por este proceso, como un destino inevitable sobre el que no cabían ya las miradas nostálgicas. La extensión de la libertad, por el contrario, era un terreno que debía ser ganado a la marea igualitarista ${ }^{5}$ y a la centralización administrativa. Estos dos fenómenos (la democratización social y la centralización) constituirían las dos amenazas fundamentales al nuevo orden; sus consecuencias político-sociales eran también dos: de una parte el despotismo de la mayoría y, de la otra, la consagración del Estado tutor.

Desde la perspectiva de Tocqueville, el derrocamiento de las monarquías absolutas no sólo no había implicado la eliminación del peligro de la arbitrariedad del poder, sino que, por el contrario, inauguraba el riesgo de un tipo de tiranía cuyo yugo sobre el individuo resultaba igual o peor al despotismo de uno sólo ${ }^{6}$. Ello en virtud de la ausencia de una estructura política cuya legitimidad y poder estuvieran por fuera de la lógica de la mayoría y de sus pasiones. La consigna de vox populi vox Dei resultaba, en este sentido, extremadamente riesgosa para las minorías (políticas o religiosas). ${ }^{7}$

En el análisis del autor, la aristocracia había sabido cumplir, en el antiguo régimen, un papel contendor de las pasiones del poder sin equivalente para los estados democráticos ${ }^{8}$. Resulta sugerente el modo en que Tocqueville celebra el papel pastoral de la nobleza, en contraposición con las objeciones que le suscita el carácter paternal del Estado moderno.

A esta primera amenaza, se suma una segunda, que Tocqueville analiza con mayor profundidad cuando aborda la cuestión del pauperismo. En efecto, este problema se vincula con que -a diferencia del antiguo régimen, en el que

5 "Creo que los pueblos democráticos tienen un gusto natural por la libertad: abandonados a sí mismos, la buscan, la quieren y ven con dolor que se les aleje de ella. Pero tienen por la igualdad una pasión ardiente, insaciable, eterna e invencible; quieren la igualdad en la libertad, y si así no pueden obtenerla, la quieren hasta en la esclavitud; de modo que sufrirán pobreza, servidumbre y barbarie, pero no a la aristocracia. (Toqueville, 1957 p.564)

6 "Las monarquías absolutas habían deshonrado el despotismo; guardémonos de que las repúblicas democráticas lleguen a rehabilitarlo, y que al volverlo más pesado para algunos, le quiten, a los ojos del mayor número, su aspecto odioso y su carácter envilecedor" (Toqueville, 1957 p.580) 7 “Cuando un hombre o un partido sufre una injusticia en los Estados Unidos, ¿a quién queréis que se dirija? ¿A la opinión pública? Es ella la que forma la mayoría. ¿Al poder ejecutivo? Es nombrado por la mayoría y le sirve de instrumento pasivo. ¿A la fuerza pública? La fuerza pública no es otra cosa que la mayoría bajo las armas. ¿Al jurado? El jurado es la mayoría revestida del derecho de pronunciar sentencias. Los jueces mismos, en ciertos Estados, son elegidos por la mayoría. Por inicua o poco razonable que sea la medida que os hiere, os es necesario sometemos a ella". (Toqueville, 1985 p.580)

8 "El poder de algunos súbditos oponía barreras insuperables a la tiranía del príncipe; y los reyes, sintiéndose revestidos a los ojos de la multitud de un carácter casi divino, tomaban, del respeto mismo que inspiraban, la resolución de no abusar de su poder. Colocados a gran distancia del pueblo, los nobles tomaban parte en la suerte del pueblo con el mismo interés benévolo y tranquilo que el pastor tiene por su rebaño; $y$, sin acertar a ver en el pobre a su igual, velaban por su suerte, como si la Providencia lo hubiera confiado en sus manos. No habiendo concebido más idea del estado social que el suyo, no imaginando que pudiera jamás igualarse a sus jefes, el pueblo recibía sus beneficios, y no discutía sus derechos “ (Toqueville, 1985 p.5) 
GRONDONA, Ana Lucia. Antídoto y utopía: Una lectura de la dimensión comunitaria en el liberalismo clásico.

la caridad estaba en manos de los particulares o de las corporaciones- en el nuevo orden, es el Estado el encargado de alimentar a los pobres y de cuidar a los desvalidos. El modo en que cumple con ello es fuertemente paternalista, aspecto que, a diferencia del papel pastoral de la aristocracia, sí sería censurado por nuestro autor. Las consecuencias de la acción del Estado tutelar eran el fomento de la ociosidad $^{9}$, de comportamientos inmorales $^{10}$, el incremento de la conflictividad social ${ }^{11}$, la extensión de situaciones de dependencia respecto del Estado ${ }^{12}$ y la inmovilización de la población ${ }^{13}$.

Así, en la descripción de Tocqueville, este Estado moderno toma a toda la sociedad y a cada individuo particular como blanco para formarlo a su antojo, "no destruye, pero impide crear, no tiraniza, pero oprime, mortifica, embrutece, extingue, debilita y reduce, en fin, a cada nación a un rebaño de animales tímidos e industriosos, cuyo pastor es el gobernante" (Tocqueville, 1957 p.634). El Estado moderno amenaza con perpetuar a los ciudadanos en una infancia signada por la impotencia y la dependencia. ${ }^{14}$

\section{El antídoto de la comunidad.}

Las asociaciones son las que en los pueblos democráticos deben ocupar el lugar de los particulares poderosos que la igualdad de condiciones ha hecho desaparecer (Tocqueville, 1985 p.475)

Tal como muestra la cita transcripta en el párrafo anterior, frente a la amenaza del despotismo de la mayoría, nuestro autor porpone el fomento del "arte de asociarse"; ello como condición misma para que los hombres

9 Dije que el resultado inevitable de la caridad legal era mantener en la ociosidad el mayor número de los pobres y mantener sus ocios a costa de los que trabajan. (Tocqueville, 2006b p.22)

10 "Al obligar a las comunas a hacerse cargo de los hijos naturales (..) hemos facilitado la inconducta de las mujeres en las clases bajas" (Tocqueville,2006a p.27)

11 "Estoy convencido profundamente de que todo sistema regular, permanente, administrativo, cuyo objetivo sea satisfacer a las necesidades el pobre, hará nacer más miserias que no puede curar, corromperá la población a la que quiere ayudar y confortar, reducirá con el tiempo a los ricos a no ser más que los agricultores de los pobres, agotará las fuentes del ahorro, detendrá la acumulación de los capitales, comprimirá el desarrollo del comercio, restringirá la actividad y la industria humana y finalmente traerá una revolución violenta en el Estado, cuando el número de los que reciben la limosna se haya vuelto casi tan grandes que el número de los que los dan, y que el indigente no pudiendo extraer nada más de los ricos empobrecidos para satisfacer sus necesidades, encontrará más fácil desnudarlos repentinamente de sus bienes que pedirles socorro". (Tocqueville 2006a: 29, itálica nuestra)

12 "La caridad legal no ejerce una menos desastrosa influencia sobre la libertad del pobre que sobre su moralidad" ( Tocqueville, 2006a p.22)

13. "Ahora bien, como en un país en el que está organizada la caridad pública, la caridad individual es casi desconocida, de ello resulta que aquellos desventurados a los que los vicios vuelven incapaces de ganarse la propia vida están condenados, bajo pena de muerte, a no irse del lugar en el que han nacido" (Tocqueville, 2006a p.22)

14 "Absoluto, minucioso, regular, advertido y benigno, se asemejaría al poder paterno, si como él tuviese por objeto preparar a los hombres para la edad viril; pero, al contrario, no se trata sino de fijarlos irrevocablemente en la infancia y quiere que los ciudadanos gocen, con tal que no piensen sino en gozar". (Tocqueville, 1957 p.633) 
"permanezcan civilizados" en los contextos en que la igualdad aumentaba (Tocqueville, 1985: 476), como garantía necesaria contra la tiranía de la mayoría y como fuerza moral de las minorías amenazadas (Tocqueville 1985: 180). Las asociaciones serían las encargadas de cumplir la vieja función de la $\operatorname{aristocracia}^{15}$. A tal fin, se contemplan cuatro tipo de asociaciones relevantes para la contención de las pasiones de la mayoría y la primacía del "juicio razonado y tranquilo": las asociaciones civiles, las asociaciones políticas, las pequeñas organizaciones privadas $y$ las asociaciones permanentes 0 geográficas (principalmente los municipios) ${ }^{16}$.

Las asociaciones civiles se presentan como una respuesta para el problema que estaba en la raíz del despotismo de la mayoría: el creciente egoísmo. Efectivamente, para Tocqueville el despotismo "ve en el aislamiento de los hombres la garantía más segura de su propia duración y procura aislarlos por cuantos medios están a su alcance" (Tocqueville, 1985 p.469). Es por ello que, si se pretende conservar la libertad, es fundamental interesar a los hombres en los asuntos públicos, particularmente en los cotidianos, pues es más fácil llamar su atención sobre éstos que sobre los grandes intereses nacionales, y así alejarlos de sus intereses privados inmediatos (p.471). Así, uno de los aspectos que más le interesan al autor en su análisis de la democracia estadounidense son sus asociaciones morales e intelectuales. Éstas son descritas como "artificiales", como esfuerzo de la voluntad humana para contener la ley de democratización creciente de las sociedades. Así, "la acción reciproca es casi nula en los países democráticos, es preciso, entonces, crearla artificialmente y esto es, "precisamente lo que las asociaciones pueden hacer" (p. 475) ${ }^{17}$.

Respecto de la comparación con el desarrollo francés, Tocqueville ve que allí las asociaciones no han sido un antídoto efectivo contra la arbitrariedad. Por un lado, en lo que hace a las asociaciones europeas, entiende que se caracterizan por hacer reinar en su interior una tiranía 
GRONDONA, Ana Lucia. Antídoto y utopía: Una lectura de la dimensión comunitaria en el liberalismo clásico.

insoportable cuyo principal objetivo no es elevar una voz disidente, ni convencer a otros racionalmente, sino combatir. De un modo sugerente, afirma que se trata de organizaciones militares, pues en ellas existe un fuerte dogma de obediencia pasiva en la que el sacrificio reemplaza al libre albedrío. En contraste, los americanos habían establecido un gobierno más "civil" en el seno de sus asociaciones (Tocqueville, 1985 p.184).

Ahora bien, Tocqueville encuentra que para que haya un extenso desarrollo de estas organizaciones es menester contar con la libertad de asociación política, menos peligrosa para la tranquilidad social de lo que se había avizorado: por el contrario,"privarse del mal peligroso de las asociaciones políticas, es privarse del desarrollo del 'remedio eficaz' de las asociaciones civiles" (Tocqueville, 1985 p.482).

Pues bien, en contraposición con el artificio de las asociaciones civiles, están las también relevantes asociaciones naturales y permanentes:

El municipio es la única asociación tan identificada con la naturaleza, que allá donde hay hombres reunidos se forma espontáneamente un municipio. (Tocqueville, 1985 p.58, énfasis nuestro)

Este aspecto nos resulta sumamente relevante, pues coincidimos en análisis tales como el de Robert Gannet et al. (2003) interesados en remarcar la primacía del municipio en el esquema tocquevillieano de democracia política $^{18}$. Así, para el ejercicio de lo que hoy denominaríamos una "ciudadanía activa", el gobierno local constituye una "escuela primaria de la libertad"19. Es ahí "donde reside la fuerza de los pueblos libres" (Tocqueville 1985: 59), el espacio en el que el pueblo ejerce su poder de modo inmediato (Tocqueville 1985: .61), la sede de un espíritu local, "un centro de vivos afectos"(Tocqueville 1985: 65) y un centro que fomenta las pasiones cívicas pero regulando su intensidad (Tocqueville, 1985 p. 65). El municipio es, en síntesis, el seno mismo del que surge la vida pública (Tocqueville, 1985 pp.62-63).

\footnotetext{
18 En efecto: "las instituciones municipales moderando el despotismo de la mayoría dan al pueblo al mismo tiempo el amor por la libertad y el arte de ser libre" (Tocqueville, 1985 p.270)

19 "El habitante de Nueva Inglaterra se encariña con su municipio porque éste es fuerte e independiente; se interesa en él, porque contribuye a dirigirlo; lo ama, porque no puede quejarse de su suerte; pone en él su ambición y su porvenir; está mezclado en todos los incidentes de la vida municipal; en la restringida esfera de su alcance, se ejercita en el gobierno de la sociedad; se habitúa a esas formas sin las cuales la libertad sólo procede por revoluciones, se penetra de su espíritu, se aficiona al orden, comprende la armonía de los distintos poderes y adquiere, en fin, ideas claras y prácticas sobre la naturaleza de sus deberes y la extensión de sus derechos" (Tocqueville 1985: 66, énfasis nuestro).
} 
Este ámbito de vínculos naturales, sede de afectos, pasiones y mesuras tiene un color fuertemente comunitario que se contrapone a las relaciones mediadas con el Estado y a la indiferencia que generan los "grandes" problemas nacionales. Este espacio aparece, entonces, como un lugar de identificación inmediata de los sujetos que puede cumplir para las naciones modernas el lugar fundamental que ocupa en EE.UU como soporte (ni totalizante ni estatizante) del orden colectivo. efecto, la estructura municipal de Estados Unidos, junto con la federal, resulta un modo aparentemente exitoso de resolver las antinomias del orden burgués, conjugando "libertad" con "igualdad", pero, sobre todo, con "estabilidad".

Este cuadro contrastaba fuertemente con el que por entonces presentaba la caótica y centralizada Francia. Para Tocqueville uno de los grandes pecados franceses, que separaba a la democracia gala de la norteamericana, era el de haber desandando los pequeños pasos dados por la Revolución en el camino de la descentralización administrativa. Imperio napoleónico mediante, Francia profundizaría la centralización inaugurada por el antiguo régimen y que había sido un detonante fundamental de la Revolución de $1789^{20}$. En consecuencia, a la hora de idear respuestas para el problema del despotismo de la mayoría, la descentralización resulta un valor importante.

Pues bien, las respuestas que plantea Tocqueville para el problema social del pauperismo (o para ser más específicos, del Estado tutelar y expansivo como consecuencia del modo de tratar ese problema) también estarían vinculadas con el mandato de descentralización. Estrechamente relacionado con el razonamiento que venimos de describir, tanto en las Memorias sobre el pauperismo de 1835 como en la Segundas memorias de 1837, recomienda organizar los esfuerzos de asistencia mediante los municipios, dado que el Estado central es un administrador demasiado lejano y hasta torpe.

De un modo más genérico, ante el problema de la pobreza, nos explica Tocqueville, hay básicamente dos tipo de respuestas: la asistencia privada y la asistencia pública. Esta última presenta grandes inconvenientes, pues genera una situación de perpetua humillación del asistido, en tanto se trata de un 
GRONDONA, Ana Lucia. Antídoto y utopía: Una lectura de la dimensión comunitaria en el liberalismo clásico.

derecho que más que consagrar la igualdad reconoce la inferioridad y tiende a fijarla como estado. Por el contrario, la asistencia privada establece un lazo moral de reconocimiento entre el pobre y el rico que se contrapone al modo en que la sociedad vive la asistencia pública como carga. Tocqueville preferirá, consecuentemente, la asistencia privada a la pública, salvo en tres casos: la escuela primaria, los momentos de "emergencia social" y las instancias de "crisis individual".

En sus trabajos sobre la cuestión del pauperismo, nuestro autor propone una máxima clara para lidiar con la cuestión social: "encontrar un modo de dar al obrero industrial como a un pequeño agricultor la esperanza y los hábitos de la propiedad" (Tocqueville, 2006b p.9). Para ello, la intervención estatal debía limitarse (salvo las señaladas excepciones) a la generalización de estos hábitos al interior de la clase obrera. Sobre este punto, se formulan tres alternativas: la cogestión obrera ${ }^{21}$, el cooperativismo y la generalización de las cajas de ahorro $^{22}$.

La primera opción remite a la posibilidad de construir una "comunidad de intereses" entre obreros y patronos, sustraída de la dinámica de la lucha. Por su parte, la segunda opción deja entrever cierta utopía cooperativista como horizonte del desarrollo del capitalismo que, aunque todavía no puede cristalizar como respuesta a la crisis que entonces atraviesa Francia, habría de desarrollarse en el futuro ${ }^{23}$. Así, nuestro autor imaginaba un futuro de florecimiento y multiplicación de cooperativas (Tocqueville, 2006b p.10).

Como podemos observar, entonces, la asociación no sólo era vista como una respuesta al problema político de la libertad ante la tiranía democrática, sino también ante la concentración de la riqueza y el crecimiento de la pobreza. Se trata, además, de una respuesta que el Estado podría fomentar sin caer en un rol tutelar.

La tercera alternativa tocquevilleana para inculcar los sanos hábitos de la propiedad es la estrategia de fomento del ahorro entre las clases populares. 
Respecto de la operatoria de esta propuesta, una posibilidad era que el Estado central concentrara los ahorros. Sin embargo, nuestro autor descarta de plano esta posibilidad, pues avizora peligros en concentrar tanto en tan pocas manos. Parece más inclinado a confiar en los estados provinciales o aún incluso municipales. La segunda cuestión era qué hacer con el dinero disponible a partir del ahorro obrero. Sobre este punto, se propone un sistema basado sobre la ayuda mutua:

Los pobres que tienen dinero para prestar lo depositarían en las manos de una administración que, mediante préstamos, se lo devolvería a los pobres que necesitarían tomarlo en préstamos. La administración no sería más que un intermediario entre estas dos clases. En realidad, sería el pobre ecónomo o momentáneamente favorecido por la fortuna que prestaría, a interés, su ahorro en el pobre pródigo o desgraciado (Tocqueville, 2006b p.18)

Tanto en la respuesta cooperativista como en la de esta suerte de microcréditos locales, observamos un fuerte componente "comunitario"; en ambos casos se minimiza la intervención estatal para dar lugar a estrategias basadas en la confianza y en la red de interrelaciones próximas. Así, en ellas el acceso a recursos no está basado en derechos adquiridos, y por ello "demandables" a un tercero (el Estado), sino en la puesta en juego de afectos y valores morales de relaciones cara a cara (vgr. la confianza y la solidaridad).

\section{El mito de la comunidad originaria. Degradación y utopía.}

Una vez establecido el carácter más "comunitario" que "social" de las respuestas tocquevilleanas, en el presente apartado nos proponemos dar cuenta del componente utópico que subyace al papel asignado a la comunidad. La propuesta de construcción de ámbitos comunitarios para lidiar con los males de la modernidad resulta, en última instancia, una apelación a la reconstrucción de una comunidad perdida y añorada. Los siguientes pasajes apoyan nuestro argumento:

Nos encontramos (con unas comunas) que, justo hasta los finales del siglo XVII, continúan estando formadas como pequeñas repúblicas democráticas, donde los magistrados son elegidos libremente por todo el pueblo y responsables ante ellos, donde la vida municipal es pública y activa, donde la ciudad se muestra todavía orgullosa de sus derechos y muy celosa de su independencia (Toqcueville, 1952 p.43). 
GRONDONA, Ana Lucia. Antídoto y utopía: Una lectura de la dimensión comunitaria en el liberalismo clásico.

La institución de las comunas introduce la libertad democrática en el seno de la monarquía feudal (Toqcueville, 1985 p.33)

Ahora bien, es propio de la estructura del "mito comunitario" la configuración de una narración sobre la degradación de tal estado de armonía. En el caso de Tocqueville, además, la degradación del modelo comunal francés era central para la explicación de la diferencia entre la democracia francesa y la de los EE.UU. Del otro lado del Atlántico existía una continuidad entre las comunas originarias y las pot-revolucionarias ${ }^{24}$, que hacían de la democracia americana una configuración contemporánea de la utopía política que prometía congeniar libertad e igualdad (gracias a "la comunidad").

En el relato de la caída (francesa) que propone Tocqueville el "pecado original" habría sido el desinterés y la pasividad ciudadana, así como el consecuente desarrollo de una casta oligárquica que centraliza el interés público ${ }^{25}$. Sin embargo, ésta tendría una función política relevante para la preservación de la libertad, pues, como veíamos más arriba, había servido para contener las arbitrariedades del poder real. La supresión de la nobleza (después de la Revolución Francesa) en condiciones en las que aún no había emergido un equivalente funcional, resultaba la principal causa del despotismo de la mayoría. Pues bien, la re-vitalización de las comunas (propuesta por Tocqueville) para cumplir con la función dejada vacante resulta, en realidad, un "regreso" al origen comunitario perdido (previo a la caída en la indiferencia) antes que el producto de la ingeniería social arbitraria. ${ }^{26}$

Pues bien, a fin de dar cuenta de esta utopía comunitaria, que entendemos remite al liberalismo como matriz teórica y no sólo excepcionalmente a Tocqueville, argumentaremos respecto de la presencia de esta dimensión en el pensamiento de John Locke. Aunque este autor no refiere directamente a algo así como "la comunidad" contrapuesta a "la sociedad", aparecen distintos grados, espacios y tipos de sociabilidad contrapuestos entre sí. Principalmente, la demarcación de los lazos entre los hombres ancla en la

24 "En el siglo XVIII el gobierno municipal de las ciudades había degenerado por todas partes en una pequeña oligarquía. Algunas familias conducían todos los asuntos según sus visiones particulares, lejos del ojo del público y sin ser responsables hacia él: es una enfermedad de la que esta administración padece en Francia entera. Todos los intendentes lo indican; pero el único remedio que se imaginan, es someter cada vez más los poderes locales al Gobierno central" (Tocqueville, 1952 p.45).

25 "El pueblo, que no se deja agarrar tan fácilmente como nos lo imaginamos a las vanas aparencias de la libertad, deja entonces por todas partes de interesarse por los asuntos del municipio y vive en el interior de sus propias paredes como un extranjero". (Tocqueville, 1952 p.45)

26 Justamente en virtud de este gesto de "regreso", más arriba hemos relativizado la propia caracterización tocquevilleana sobre la artificialidad de las asociaciones civiles. Ver nota 17. 
distinción entre "lo natural” y "lo artificial". Nuestra interpretación se sostiene en divisar, justamente en esta diferenciación, aspectos concordantes con las divisiones entre los lazos de tipo "social" (mediados, instrumentales, modernos, basados en el cálculo, etc) y los lazos de tipo "comunitario" (inmediatos, naturales, originarios, espontáneos, etc.) A partir de allí, construiremos nuestro argumento $^{27}$.

Esta propuesta de interpretación se sostiene, además, en trabajos antecedentes como el de Grant (1988), quien recupera, a partir del análisis de los elementos más histórico-antropológico, diversas instancias comunitarias previas al pacto social y al establecimiento de la sociedad civil ${ }^{28}$. Al respecto, resulta singularmente pertinente la siguiente afirmación:

En las discusiones contemporáneas, tenemos la expectativa de que lo opuesto a individualismo sea algo así como comunitarismo; la implicación del término es esta en tensión con la comunidad o con la sociedad. El opuesto a individualismo en el pensamiento lockeano, sin embargo, no es comunidad sino jerarquía (Grant, 1988 p. 51)

En este sentido, debemos señalar que para John Locke, a diferencia de lo que ocurría con Thomas Hobbes (y aún con Jean Jaques Rousseau) el hombre es sociable por naturaleza $(\S 77)^{29}$. Esto no sólo marca una diferencia relevante al interior del conocido modelo iusnaturalista recuperado por Norbeto Bobbio (2000), sino que también nos pone a resguardo de las lecturas que toman el pacto social como una ruptura absoluta entre un momento natural (de puro atomismo individual) y un momento colectivo y artificial (vgr. el argumento hobbesiano). En efecto, aún cuando la distinción natural-artificial sea fundamental a la hora de analizar los distintos lazos que unen a los hombres, si

\footnotetext{
27 Construimos este argumento a partir del Segundo tratado sobre el gobierno civil.

28 En particular, Grant señala tres 1) la familia extensa formada por padres, niños, siervos y esclavos, en la que el gobierno es doméstico y no político; 2) la monarquía patriarcal, momento en que el padre por consentimiento tácito pasa a establecerse como autoridad política, cuyo poder es absoluta prerrogativa individual; finalmente, 3) la conjunción de numerosas familias reunidas bajo un único jefe político, particularmente en circunstancias de guerra. En esta lectura hay una distinción que nos resultará sumamente relevante entre el individualismo teórico-filosófico que plantea Locke -que funcionaría como premisa moral en su pensamiento- y el "comunitarismo" antropológico -que aparecería en los apartados más históricos del autor- que reconoce el carácter sociable del hombre. Efectivamente, es a partir del debate con Sir Filmer -más desarrollado en el Primer tratado- que Locke debe contrargumentar la conclusión de ese autor respecto de la naturalidad del gobierno y la dependencia de los hombres, motivo que lo conduce a insistir en la libertad natural del hombre. Así, el estado de naturaleza es un argumento lógico para sostener una premisa moral, razón por la que no cabe interpretarlo ni como un postulado metafísico ni como un hecho histórico.

29 En el caso de las citas del Segundo tratado... de John Locke, hemos decidido indicar el número de parágrafo, antes que el de página. Ello a fin de facilitar la consulta del texto en todas sus ediciones.
} 
GRONDONA, Ana Lucia. Antídoto y utopía: Una lectura de la dimensión comunitaria en el liberalismo clásico.

el hombre es social por naturaleza, la artificialidad de la unión con otros será siempre relativa.

Pues bien, en el estudio del Segundo tratado nos encontramos con un primer ámbito de sociabilidad que es caracterizada como originaria, atávica y hasta bíblica: se trata de la comunidad de tierras en la que originalmente Dios dispuso al género humano ${ }^{30}$. Si esta primera disposición es natural y primaria, será el arte humano, concretamente, mediante el trabajo, el que funcionará como operador del tránsito hacia formas más complejas de sociabilidad:

Tampoco es tan extraño como quizás pudiera parecernos antes de recapacitar en ello que la propiedad del trabajo de cada hombre pueda sobrepasar en valor a la comunidad de tierras, porque es el trabajo, sin duda alguna, lo que establece en todas las cosas la diferencia de valor (Locke, 1999, §40)

En este pasaje tenemos no sólo la enunciación de la teoría del valor, sino también del trabajo como operador necesario para pasar de la tierra natural a una tierra pasible de ser tratada como propiedad privada, el pasaje de "lo uno" indiviso a "lo múltiple diverso". Aunque en principio, no cabría una valoración moral peyorativa de este tránsito (como sí sería el caso para Rousseau), en algunos pasajes del Segundo tratado se sugiere cierta antropología negativa, y con ello la transición de esta primera comunidad natural a la delimitación de distintos grupos aparece como una degradación del feliz estado de libertad, igualdad y paz que Locke delimita como estado de naturaleza ${ }^{31}$.

De este modo, al este primer estadio de vida en común le sigue otro (en algún sentido, más degradado) en el que "diferentes comunidades establecieron los límites de sus distritos respectivos y regularon por medio de leyes, dentro de esas mismas, las propiedades de los individuos y las de la sociedad a que pertenecían” ( $\$ 45$, énfasis nuestro). De acuerdo a la reconstrucción que proponemos aquí, el segundo momento (aún en Estado de Naturaleza), en el que aparecen la escasez, el trabajo, la propiedad privada y el dinero, se organizaría en comunidades. En ellas rige, inmediatamente, la ley

30 Por esta ley común a todos (la ley natural), él y todos los demás hombres forman una sola comunidad, constituyen una sola sociedad, y eso los distingue del resto de las criaturas (Locke, 1999 §127).

$31 \mathrm{Si}$ no fuese por la corrupción y los vicios de ciertos hombres degenerados, no habría necesidad de ninguna otra ley, ni de que los hombres se apartasen de esa alta y natural comunidad, para asociarse en combinaciones de menor importancia (§127) 
natural que manda cuidar los bienes, la libertad y la persona (§6). Este punto es central, pues marca la existencia de un tipo de convivencia que no depende de la existencia de un pacto social que instituya un orden legal positivo legítimo.

Una consecuencia importante de lo expuesto hasta aquí es que no se deduce del texto un antagonismo fundamental entre individuo y la comunidad (confirmando la hipótesis de Grant), ni siquiera puede decirse que antes del orden civil hayan existido solamente individuos aislados; por el contrario hay formas desarrolladas de sociabilidad. Sin embargo, los hombres salen (y deben salir) del Estado de Naturaleza, ¿por qué si este es tan perfecto que hasta admite grados de organización en común de la vida? En este punto (como en otros) seguimos el análisis de Sheldon Wolin (1974), para quien la necesidad de construir una sociedad civil se origina no en el Estado de Naturaleza, ni en el Estado de Guerra (lectura que homologaría Locke a Hobbes), sino en "el estado caído de naturaleza". Los individuos se ven impelidos a formar una sociedad política en tanto están inseguros respecto de sus derechos y llenos de temores, producto de la corrupción y la perversidad de algunos hombres degenerados. En efecto, en el texto de Locke hay argumentos para delinear este estado como una degeneración del estadio original, una suerte de "desmoralización" de la comunidad originaria. Desde la perspectiva de Grant (1988), ésta sería resultado de la generalización del dinero y de la agricultura, combustibles para la corrupción y la ambición humana.

Ahora bien, este estado original, una vez perdido, funcionar como impulso e ideal para un nuevo tipo de orden, brindando las coordenadas que deberían guiarlo ${ }^{32}$ :

Sólo existe sociedad política allí, y exclusivamente allí, donde cada uno de los miembros ha hecho renuncia de ese poder natural, entregándolo en manos de la comunidad para todos aquellos casos que no le impiden acudir a esa sociedad en demanda de protección para defensa de la ley que ella estableció. Vemos, pues, que al quedar excluido el juicio particular de cada uno de los miembros, la comunidad viene a convertirse en arbitro $\mathrm{y}$, interpretando las reglas generales y por intermedio de ciertos hombres autorizados por esa

32 "En suma: los <<defectos>> del estado caído eran conocibles solamente a la luz de las normas encarnadas en el estado ideal (...) Esto se ve en los <<remedios>> (un ejemplo significativo de uso que implica restauración, antes que innovación) para el estado caído. Dichos remedios son: una ley común, un método para el juicio imparcial y un poder que ejecute; los tres retrotraen a ordenamientos vigentes en el estado ideal" (Wolin, 1974 pp. 329-330) 
GRONDONA, Ana Lucia. Antídoto y utopía: Una lectura de la dimensión comunitaria en el liberalismo clásico.

comunidad para ejecutarlas, resuelve todas las diferencias que pueden surgir entre los miembros de dicha sociedad en cualquier asunto de Derecho, y castiga las culpas que cualquier miembro haya cometido contra la sociedad (§87, la itálica es nuestra)

Tal como afirma Sheldon Wolin (1974) "una atenta observación del lenguaje empleado por Locke para describir el contrato fundamental" revela que, en la enunciación del autor, se supone una comunidad preexistente a la sociedad civil y a la que deben resignarse los poderes naturales" (45, subrayado nuestro). De hecho, en un principio la comunidad política debe, necesariamente, presentarse como una unidad indivisa, pues es la primera sede del poder supremo ( $\$ 149$ y §95) y sólo en tanto actué como una única voluntad unánime podrá determinar legítimamente como segundo centro del poder supremo la voluntad de la mayoría, garantizando con ello la continuidad del orden. El orden político ( $y$, podríamos pensar "social") no nace, entonces, de la mera dispersión de individuos.

En tanto Locke comprendió la centralidad de la premisa de a-sociabilidad para la derivación del poder absoluto, realizó un importante esfuerzo teórico por postular formas de sociabilidad que no dependieran de la autoridad política y que incluso fueran previas a la constitución de la sociedad civil. Antes de Estado, hubo sociedad civil, antes comunidad política, antes comunidades de individuos y antes comunidad originaria. A partir de esta concepción, no habría argumentos para sostener que el único modo de garantizar el orden sea mediante una autoridad absoluta que permanezca en estado de naturaleza respecto de los súbditos. Según expone Wolin, "Locke invirtió las prioridades tradicionales para establecer la sociedad como sostén del orden político, en lugar de lo contrario" (Wolin, 1974 p. 332).

Así, en el texto de Locke aparecen lazos entre los hombres en estado de naturaleza que carecen de mediaciones artificiales y legales, y que, por contrario, se presentan como naturales e inmediatas. Nuestra propuesta de lectura propone vincular estos lazos al registro de lo comunitario como aquello que se opone a lo social-artefactual en la díada "comunidad-sociedad" (ver de Marinis, 2010).

Pues bien, estas instancias comunitarias previas al pacto social, lejos de ser un pasado del que hay que huir presentan un estado que cabe intentar 
recomponer. Es justamente este mito comunitario (que une el origen con el futuro) el que entendemos remite a la utopía de una sociedad autorregulada, automática en la que las mediaciones políticas (y arbitrarias) puedan ser relevadas.

\section{Reflexiones finales}

La reinvención de la comunidad está vinculada a una nueva concepción acerca del modo en que el sujeto de gobierno se colectiviza (Rose, 2000 p.140)

El recorrido que hemos propuesto aquí, nos permite relativizar la novedad de tal concepción. Aún cuando la teoría política y económica que denominamos "liberalismo" se haya resistido a las soluciones "comunitaristas" que pretendían un regreso al Antiguo Régimen, con ello se impugnaba su organización jerárquica antes que la postulación de órdenes de convivencia "espontáneos" cargados de moralidad. Del mismo modo, será el componente totalitario y autoritario el que se impugne en la crítica a las comunidades efervescentes vinculadas a los fascismos. Nuevamente, será la arbitrariedad de una planificación totalizante y centralizada la que se objetará en el caso de la comunidad proletaria de los socialismos reales.

Sin embargo, el liberalismo no renuncia por ello a su propia dimensión comunitaria. Entendemos que ella puede analizarse tomado en cuenta dos aspectos. Por una parte, frente a la cuestión social, tempranamente, el liberalismo pondrá en disponibilidad tecnologías comunitarias para la administración de diversos problemas sociales (vgr. el pauperismo). Desde la perspectiva liberal, éstas serían capaces de responder a la contradicción del orden burgués moderno sin los peligros (para la libertad) propios de las técnicas "sociales", vinculadas (además) a la consolidación de un Estado centralizado y especializado (sobre el que luego advertiría Max Weber).

Ahora bien, las propuestas comunitaristas (vgr. las que analizamos en el pensamiento de Tocqueville) tienen un estatuto singular, que no puede reducirse a la de respuesta contingente frente a una coyuntura determinada. Por el contrario, hemos intentado mostrar, que responden a una concepción de la naturaleza misma del orden colectivo; o, mejor, de su naturaleza perdida y que es posible (, deseable y necesario) re-crear. En este sentido, la estructura 
GRONDONA, Ana Lucia. Antídoto y utopía: Una lectura de la dimensión comunitaria en el liberalismo clásico.

del mito de la comunidad degradada (que analizamos tanto en Tocqueville como en Locke) supone la delimitación de una utopía comunitaria, que sería capaz de cancelar una espera; espera que es también una forma (no exactamente conservadora) de añoranza. En este sentido, no deberíamos reducir en nuestro análisis la comunidad (neo)liberal a la mera "instrumentalización" de un ámbito de sociabilidad afectiva y moral. La comunidad es también una promesa.

La construcción mítica muestra que "la comunidad" esta permanente atravesada por tensión de presentarse como algo que se da por (pre)existente y algo que se nos interpela a construir (Rose, 1996). Pareciera que todo llamado a la comunidad, para ser efectivo, debe presentarse como un "regreso".

Pues bien, en los llamados del neoliberalismo contemporáneo, la comunidad parecería renacer entre los escombros de "lo social". Sin embargo, entendemos que, así como no puede presumirse "la novedad" del antídoto comunitario, tampoco parece adecuado pensar su re-emergencia como mero "relevo" de las tecnologías sociales. Por el contrario, nos inclinamos a poner como centro de la reflexión los procesos de hibridación que articulan (o re articulan) las lógicas de lo social y de lo comunitario en el gobierno de las poblaciones. Ello supondría dar cuenta, además, de los modos en que esas hibridaciones mutan y se transforman. Una tarea más minuciosa, y sin duda más gris, que la de anunciar (periódicamente) supuestas muertes y (re)nacimientos.

\section{Referencias Bibliográficas}

Bernstein, Basil. 1998. Pedagogía, control simbólico e identidad Madrid: Morata,1998.

Bobbio, Norberto.2000. El modelo iusnaturalista, en Sociedad y estado en la filosofía moderno. El modelo iusnaturalista y el modelo hegeliano-marxiano. Buenos Aires: Fondo de Cultura Económica, 2000

de Marinis, Pablo.2005. 16 comentarios sobre la s sociología s y la s comunidad es Papeles del CEIC \# 15, marzo 2005.

de Marinis, Pablo.2010. Comunidad: derivas de un concepto a través de la historia de la teoría sociológica, en Papeles del CEIC, vol. 2010/1, introducción al monográfico sobre Comunidad, CEIC Centro de Estudios sobre la Identidad Colectiva, Universidad del País Vasco, http://www.identidadcolectiva.es/pdf/intro.pdf, 2010.

de Tocqueville, Alexis. 1952 [1856]. L'Ancien régime et la Révolution Paris: Les Éditions Gallimard en http://classiques.uqac.ca/classiques/De tocqueville alexis/ancien regime/ancien regime.html, 1952. 
Leviathan - Cadernos de Pesquisa Política, n. 4, pp. 89-107, 2012.

de Tocqueville, Alexis.1957 [1840]. La democracia en América, T2 México: Fondo de cultura económica, 1957.

de Tocqueville, Alexis.1985 [1830]. La democracia en América, T.1 México: Alianza Editorial, 1985.

de Tocqueville, Alexis. 2006a [1835]. Mémoire sur le paupérisme .Mémoire présenté à la Société académique cherbourgeoise, en Mémoires de la Société académique de Cherbourg, Edicion electrónica en 2006. Traducción nuestra. Edición electrónica realizada en 2006. http://classiques.uqac.ca/classiques/De tocqueville alexis/memoire pauperisme 1/memoire pauperisme 1.html

de Tocqueville, Alexis. 2006b [1837]. Second mémoire sur le paupérisme. Traducción nuestra Edición electrónica en 2006. http://classiques.uqac.ca/classiques/De tocqueville alexis/memoire pauperisme 2/memoire pauperisme 2.html

Donzelot, Jacques. 1995. L' invention du social. Essai sur le déclin des passions politiques Paris: Éditions du Seuil, 1995.

Ferrater Mora, José. 1964 Diccionario de filosofía. Buenos Aires: Sudamericana, 1964.

Foucault, Michel. 2008. El nacimiento de la biopolítica Buenos Aires: Fondo de Cultura Económica , 2008.

Gannett Robert T. et al.2003. Ninepins in Tocqueville's Township en The American Political Science Review, Vol. 97, No. 1. Feb., 2003.

Grant, Ruth. 1988. Locke's Political Anthropology and Lockean Individualism , en The Journal of Politics, Vol. 50, No. 1. Feb., 1988.

Hobbes, Thomas. 1997 [1651]. Leviatán Barcelona: Editorial Altaza, 1997.

Locke, John1999 [1689]. Segundo tratado sobre el gobierno civil Madrid Biblioteca Nueva

Polanyi Karl. 1989.La gran transformación. Madrid: La Piqueta. 1989.

Rose, Nicolás. 2000. Community, Citizenship, and the third Way, en American Behavioral Scientist, Vol. 43, No. 9, 2000.

Rose, Nikolas. 1996. The death of the social? Re-figuring the territory of government en Economy and Society. Open University, U.K., Vol. 25, № 3, 1996.

Wolin, Sheldon.1974. Política y perspectiva : continuidad y cambio en el pensamiento político occidental Buenos Aires: Amorrortu, 1974.

Submetido em 2011-08-22

Aceito em 2012-02-16 